Prokofyeva G.M., Candidate of Chemical Sciences, Sennik A.S., PhD Student, Matveeva K.M., Knysh N.V. Igor Sikorsky Kyiv Polytechnic Instiute, Kiev

37, build. 4, Peremohy Ave., 03056 Kiev, Ukraine, e-mail: prokofyeva_g_n@ukr.net

\title{
Development of Anticorrosic Technical Detergents
}

In operation of gas turbine plants pollution of aerosol deposits of internal elements of gas-air tracks occurs. This leads to a significant consumption of their power, contributes to increasing energy costs, reducing the operational reliability of installations, through the activation of corrosion and erosion processes. The main requirements for the components of the washing composition are: high washing ability and low corrosion activity. The choice of anticorrosive ingredients for technical detergents provides for the absence of an effect on the effectiveness of the washing composition. One of the important characteristics of technical detergents is its corrosive properties. Exactly this indicator is relevant to the evaluation of the service life of the equipment, so it was the interest to study the dependence of the rate of corrosion on surfactants. The modification of the existing TD and the polyfunctional action ingredients introduced into their composition, which promote the inten-sification of complexing and anticorrosion properties has studied. Bibl.5, Fig.3, Table 1.

Key words: technical detergent, surfactants, corrosion, polymers, spectrophotometry, corrosion rate.

\section{References}

1. Mezheritskiy A.D. [Units of turbo-supercharging system of marine engines]. Leningrad : Sudostroenye, 1986. 248 p. (Rus.)

2. Pat. 2259393 RU. [Detergent for cleaning the metal surface]. I.T.Fedotov. Published 08.05.2005. (Rus.)

3. Pat. 2280070 RU. [Detergent for cleaning the metal surface]. A.V.Lyubomirov. Published 10.03.2006. (Rus.)
4. Nizhnik V.V., Nizhnik T.Yu. [Physical chemistry of polymers]. Kiev : Fitosotsiotsentr, 2009. 424 p. (Ukr.)

5. Prokofyeva G.M., Bilousova N.L., Sudarushkina T.V. [Technical detergents. Corrosive and protective properties of individual ingredients]. Himichna promislovist Ukrayini. 2007. No. 4. P. 21-23. (Ukr.)

Received January 25, 2018

Семейко К.В.1, канд. техн. наук, Сидоренко Н.A.1, аспирант, Чумак Р.E. 2 1 Институт газа НАН Украины, Киев ул. Дегтяревская, 39, 03113 Киев, Украина, e-mail: k_simeyko@ukr.net 2 Київський політехнічний інститут імені Ігоря Сікорського, Київ просп. Перемоги, 37, 03056 Київ, Україна, е-таil: roma.chuтаk25@gmail.com

\section{Исследование влияния механиковибрационной звуковой частоты на гидродинамику псевдоожиженного слоя}

\begin{abstract}
Рассмотрен процесс термической обработки малого количества твердого материала с максимальным контактом фаз «твердое вещество - газ» в псевдоожиженном слое. Одним из возможных вариантов создания псевдоожиженного слоя является пропускание звуковых волн через твердый зернистый материал. Проведено визуальное исследование гидродинамики создания псевдоожиженного слоя звуковыми волнами. Рассмотрена проблема уноса твердого материала. Определена оценка влияния траектории движения частичек на теплофизические свойства псевдоожиженной системы. Применение звуковых волн должно увеличить интенсивность теплообмена внутри и между твердой и газовой фазами. Разработана схема конструкции реактора для получения пироуглеродных покрытий при малом количестве обрабатываемого материала. Библ. 9, puс. 4.

Ключевые слова: электротермический псевдоожиженный слой, пироуглерод, пиролиз углеводородных газов.
\end{abstract}

(C) Семейко К.В., Сидоренко Н.А., Чумак Р.Е., 2018 
В Институте газа НАН Украины, помимо основных исследований электротермического псевдоожиженного слоя [1-5], возникла необходимость термической обработки малого количества твердого материла в связи с запросом Института сверхтвердых материалов НАН Украины, а также с другими исследованиями. Традиционный способ образования псевдоожиженного слоя ожижающим агентом, в данном случае газом, может привести к уносу материала через газораспределительную решетку или колпачки, что необходимо исключить.

Альтернативным способом является использование магнито- и виброкипящего слоя. В первом случае необходимо наличие магнитных свойств у твердых частичек, однако не все частички обладают магнитными свойствами. При использовании классического виброкипящего слоя основным недостатком представляются сложности расположения нагревательных элементов. Одним из перспективных вариантов решения данной задачи является использование звуковых волн для создания псевдоожиженного слоя, который также можно отнести к виброкипящему слою.

Цель работы - исследование влияния звуковых волн на гидродинамику твердой фазы псевдоожиженного слоя, нахождение оптимальных звуковых характеристик для эффективного влияния на теплообмен твердой фазы.

Эта эффективность проявляется в активности и траекториях движения частичек, что влияет непосредственно на теплообмен в псевдоожиженном слое.

Исследования основывались на визуальном наблюдении за движением частиц под действием звуковых волн и теоретическом сопоставлении траектории циркуляции частичек с теплообменными характеристиками.

Использование звуковых волн является не новым направленим в разных отраслях про-

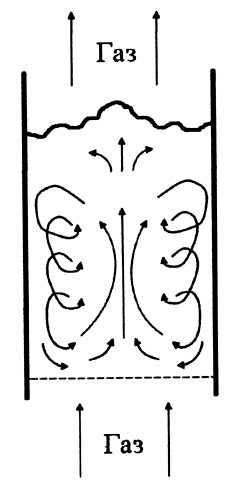

Рис.1. Схема циркуляционных потоков твердых частичек в аппаратах псевдоожиженного слоя с малым диаметром. мышленности. Ультразвуковая обработка металлов применяется в металлургии для улучшения их качества. Под действием ультразвуковых колебаний из расплава выделяется растворенный в нем газ, удаляются неметаллические включения. Когда производят закалку, ультразвуковые колебания повышают охлаждающую способность закалочной жидкости, разрушают паровую рубашку, которая образуется вокруг закаливаемой детали, а также повышают механические свойства и прокаливаемость стали. При сжигании окисленных углей ультразвук усиливает эффективность сгорания до 20 раз, что дает значительную экономическую выгоду. В химической промышленности звуковые волны используют для ускорения различных производственных процессов [6].

Акустические волны применяются при синтезе многостенных углеродных нанотрубок в псевдоожиженном слое. Синтезируемые нанотрубки обладают большой адгезией и образуют микроагрегаты и более масштабные структуры, которые плохо поддаются псевдоожижению. Гомогенизация слоя агломератов нанотрубок обеспечивается вводом в реактор акустической волны через холодную подрешеточную область. При выборе резонансной частоты акустического воздействия в диапазоне 100-250 Гц достигается эффективная однородность слоя, обеспечивающая высокую степень конверсии углеродсодержащего газа [7].

Характер движения частичек в объеме псевдоожиженного слоя в значительной степени зависит от конструктивных особенностей аппаратуры. Для аппаратов малого диаметра характерна направленная циркуляция твердого материала в пседоожиженном слое: твердые частички в основном движутся восходящим потоком вдоль центральной оси, а у стенок наблюдается спадающее движение частиц, как показано на рис.1. При этом частицы одновременно находятся в хаотическом пульсирующем движении. Наиболее ярко выражен направленный характер движения твердой фазы в аппаратах с конической основой. Максимальный коэффициент теплоотдачи наблюдается на некотором расстоянии от центральной оси аппарата [8]. Приемлемым результатом исследований будет считаться повторение циркуляционных потоков, показанных на рис.1.

Эксперименты проводились в установке, представляющей собой электродинамический громкоговоритель, на котором установлен экспериментальный сосуд в виде цилиндра $(\mathrm{d}=$ $=0,03$ м), и между ними установлена мембрана в виде листа бумаги. Конечно, для термических 


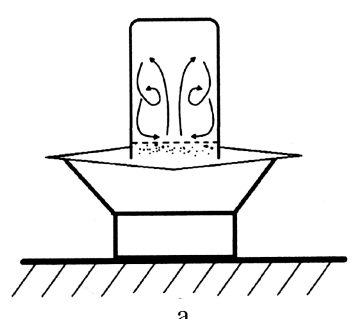

a

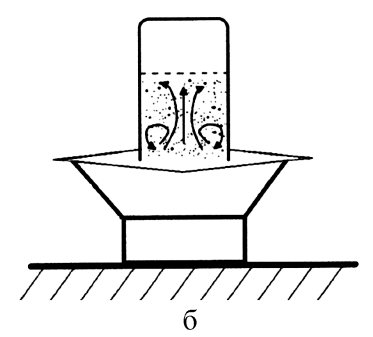

Рис.2. Движение частиц при $\mathrm{f}=350$ Гц (а) и 5500 Гц (б).

процессов лист бумаги не является пригодным, однако его можно будет заменить другим звукопроницаемым и термостойким материалом. Звуковые волны создавались компьютерной программой генерирования частот. Давление звука 80 дБ, диапазон частот $\mathrm{f}=300-6100$ Гц. Материал для исследования - кварцевый песок: навески массой 2 г, фракция $\leq 0,315$ мм, насыпная плотность 1,559 г/ $\mathrm{cm}^{3}$. Проведена серия из около 30 опытов с различными комбинациями частот и амплитуд звуковых волн, самые успешные из которых описаны далее.

При $\mathrm{f}=350$ Гц наблюдалось активное движение частиц из центра вверх и к стенкам, при опускании частиц вниз наблюдалось движение частичек к центру нижней части цилиндра. Максимальная высота $\mathrm{h}_{\max }=4$ см, максимальная плотность слоя находилась внизу цилиндра. Траектория движения частиц показана на рис. 2 ,а.

При $\mathrm{f}=5500$ Гц и $\mathrm{h}_{\max }=3$ см плотность слоя на высоте 2 см стала больше, чем в предыдущих опытах. Траектория движения частиц приведена на рис.2,б.

Самый интересный результат получен при $\mathrm{f}=3400$ Гц: частички практически «зависают» в воздухе с минимальным колебательным хаотическим движением. Плотность слоя приблизительно одинакова по всему объему цилиндра. Условное незначительное движение частиц показано на рис.3.

Интенсивность теплообмена в псевдоожиженных системах, показанных на рис.2, зави-

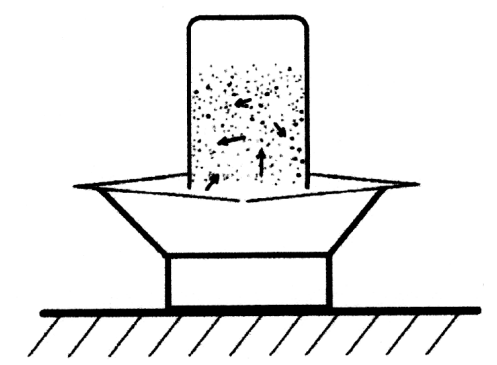

Рис.3. «Зависание» частиц при $\mathrm{f}=3400$ Гц. сит от скорости движения частиц и теплопроводности газа, который заполняет пространство между частичками. Данная траектория движения частиц интенсифицирует теплообмен, если нагревательный элемент находится внутри либо снаружи аппарата. Теплота от поверхности нагрева передается пакетами твердых частиц и газом, который находится между частицами и поверхностью. В случае, представленном на рис.2,б, теплота неравномерно распределяется по всему слою. Так как более мелкие частички будут вверху, это можно использовать для нагревания определенной фракции материала, если фракционное разделение недоступно. В системе, представленной на рис.3, теплота в основном передается газом, который находиться между частичками.

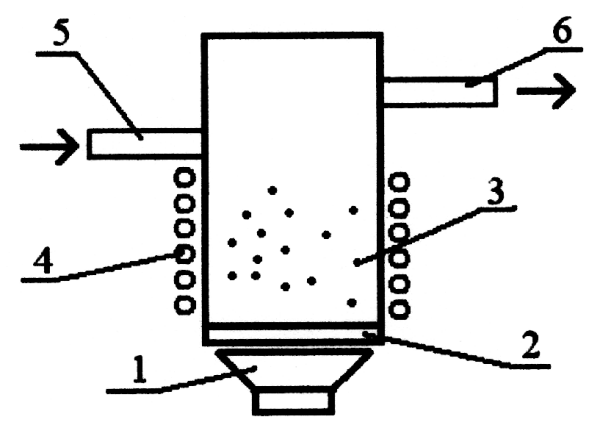

Рис.4. Схематическая конструкция реактора для нанесения пироуглеродных покрытий для малого количества материала: 1 - динамик; 2 - железная мембрана; 3 - частичка псевдоожиженого слоя; 4 - нагреватель; 5 - ввод газа; 6 - выход газа.

Известно, что при пропускании тока через псевдоожиженный слой, осциллограммы пульсации давления и электросопротивления в большинстве случаев совпадают по частоте. С повышением расхода псевдоожижающего газа частота пульсаций не меняется, амплитуда пульсаций давления и электросопротивления увеличивается [9]. В связи с этим вызывает интерес изменение электросопротивления в случае, представленном на рис.3. По мнению автора, электросопротивление будет практически одинаковым по всей высоте слоя.

На основе проведенных опытов и анализа результатов можно предложить схематическую конструкцию реактора для нанесения пироуглеродных покрытий для малого количества материала (рис.4).

В данном реакторе необходимо использовать углеродосодержащий газ тяжелее воздуха, например, пропан-бутановую смесь. Санитарные нормы звукового загрязнения ограничивают возможности использования данного реактора, од- 
нако эту проблему можно решить, окружив реактор звукоизоляционной конструкцией.

Полученные результаты в дальнейшем можно использовать при разработке новых аппаратов с псевдоожиженным слоем, где невозможно (или недостаточно) в качестве ожижающего агента использовать газ или жидкость. Также имеет перспективу дальнейших исследований гомогенизация слоя агломератов при помощи звуковых волн.

\section{Выводы}

Траектория движения частиц под действием звуковых волн зависит от многих факторов: частоты, амплитуды, давления звука, а также характеристик твердой фазы. Применение звуковых волн должно увеличить интенсивность теплообмена внутри и между твердой и газовой фазами псевдоожиженного слоя. Установлено, что некоторые из полученных траекторий движения твердой фазы, а именно те, при которых частицы движутся вверх и к стенкам аппарата, будут положительно влиять на теплообмен в установках псевдоожиженного слоя, в которых нагревательный элемент расположен у стенок реактора или опущен в псевдоожиженный слой, или где применяется нагрев пропусканием электрического тока.

К основным проблемам применения звуковых волн для создания псевдоожиженного слоя относится термическая и механическая устойчивость прослойки между источником звуковых волн и псевдоожиженным слоем. Одним из вариантов ее решения является применение металлической мембраны и изготовление электродинамического громкоговорителя из термостойких материалов. Также следует отметить требования санитарных норм звукового загрязнения, однако эту проблему можно решить, поместив реактор внутрь звукоизоляционной конструкции. Результаты опытов можно в дальнейшем использовать при разработке новых аппаратов с псевдоожиженным слоем, где невозможно (или недостаточно) в качестве ожижающего агента использовать газ или жидкость, а также для гомогенизации слоя агломератов. Этот метод может применяться к гранулометрически неодно- родным материалам, для которых требуется обработка в псевдоожиженном слое. Таким материалом может являться графит природного происхождения, так как размеры его частиц могут колебаться от 0,063 до 0,315 мм, что вызывает трудности его псевдоожижения традиционным способом.

\section{Список литературы}

1. Богомолов В.А., Кожан А.П., Бондаренко Б.И., Ховавко А.И., Семейко К.В. Капсулирование кварцевого песка пироуглеродом в электротермиеском псевдоожиженном слое. Энерготехнологии и ресурсосбережение. 2013. № 5. С. 36-40.

2. Семейко К.В. Использование электротермического псевдоожиженого слоя в качестве внешнего нагревательного элемента реактора. Энерготехнологии и ресурсосбережение. 2015. № 1. С. 58-64.

3. Семейко К.В., Безуглый В.К., Кожан А.П., Бондаренко Б.И. Исследование процесса осаждения твердого углерода во время пиролиза углеводородных газов. Энерготехнологии и ресурсосбережение. 2015. № 2. С. 58-64.

4. Simeiko K. Thermal influence of microdischarge plasma on the process of receiving of quartz sand encapsulated by pyrocarbon. Proccedings of the $\mathrm{Na}$ tional Aviation University. 2014. № 2. P. 131-135.

5. Сімейко К.В. Теплові характеристики реактору для одержання капсульованого піровуглецем кварцевого піску при проходженні процесу піролізу метану. Вісник СумдУ. Сер. Технічні науки. 2013. № 4. С. 119-123.

6. Хорбенко И.Г. Звук, ультразвук, инфразвук. М. : Знание, 1986. $192 \mathrm{c.}$

7. Бородуля В.А., Рабинович О.С., Виноградов Л.М. и др. Синтез высокотехнологических материалов в кипящем слое : Новые подходы и перспективы. Тезисы докладов и сообщений XIV Минского международного форума по тепло- и массообмену, Минск, 10-13 сент. 2012 г. Минск : Институт тепло- и массообмена им. А.В.Лыкова НАН Беларуси, 2012. С. 2280-231.

8. Гельперин Н.И., Айнштейн В.Г., Кваша В.Б. Основы техники псевдоожижения. М. : Химия, 1967. $664 \mathrm{c}$.

9. Кожан А.П. Использование электротермических псевдоожиженных систем применительно к выскотемпературной переработке природного газа : Автореф. дис. ... канд. техн. наук. Киев, 1979. 19 с.

Поступила в редакцию 06.06.18 
Сімейко К.В.1, канд. техн. наук,

Сидоренко М.A.1, аспірант, Чумак Р.Є.2

1 Інститут газу НАН України, Київ

вул. Дегтярівська, 39, 03113 Київ, Україна, e-mail: k_simeyko@ukr.net

2 Київсъкий політехнічний інститут імені Ігоря Сікорсъкого, Київ просп. Перемоги, 37, 03056 Київ, Украӥна, e-mail: roma.chumak25@gmail.com

\section{Дослідження впливу механіковібраційної звукової частоти на гідродинаміку псевдозрідженого шару}

Розглянуто процес термічної обробки малої кількості твердого матеріалу з максимальним контактом фаз «тверда речовина - газ» у псевдозрідженому шарі. Одним 3 можливих варіантів створення псевдозрідженого шару є пропускання звукових хвиль через твердий зернистий матеріал. Проведено візуальне дослідження гідродинаміки створення псевдозрідженого шару звуковими хвилями. Розглянуто проблему виносу твердого матеріалу. Визначено оцінку впливу траєкторії руху частинок на теплофізичні властивості псевдозрідженої системи. Застосування звукових хвиль має збільшити інтенсивність теплообміну всередині та між твердою й газовою фазою. Розроблено схему конструкції реактора для отримання піровуглецевих покриттів при малій кількості оброблюваного матеріалу. Бібл. 9, puс. 4.

Ключові слова: електротермічний псевдозріджений шар, піровуглець, піроліз вуглеводневих газів.

Simeiko K.V.1, Candidate of Technical Sciences,

Sidorenko M.A.1, PhD Student, Chumak R.E. ${ }^{2}$

1 The Gas Institute of National Academy of Sciences of Ukraine, Kiev

39, Degtyarivska Str., 03113 Kiev, Ukraine, e-mail: k_simeyko@ukr.net

2 Igor Sikorsky Kiev Polytechnic Institute, Kiev

37, Peremohy Ave., 03056 Kiev, Ukraine, e-mail: roma.chumak25@gmail.com

\section{Investigation of the Influence of Mechanical-Vibrational Sound on Hydrodynamics of a Fluidized Bed}

The main purpose of this paper is to investigate the concept of a heat treatment of a small amount of solid material with the maximum contact of the gas and solid material. The solution of this problem consists in passing the process in a fluidized bed. However, the key issue of this solution is the problem of entrainment of solid material. Among feasible ways of the fluid bed hydrodynamics creation is a sound waves transmission through a solid granular material. A visual study on the fluid bed hydrodynamics creation with sound waves was conducted. The estimation of the impact of the trajectory of the particles on the thermophysical properties of the fluidized system was determined. The exploitation of sound waves should increase the intensity of heat exchange inside and between the solid and gas phases. Reactor design scheme for pyrocarbon coatings creation was developed. This scheme implies a small amount of material to be treated. The results obtained can be subsequently applied in the process of developing new fluidized bed apparatus, when the usage of a gas or a liquid as a fluidizing agent is technically impossible (or insufficiently). The prospects for further research include homogenization of the agglomerate layer by means of sound waves. Bibl. 9, Fig. 4.

Key words: electrothermal fluidized bed, pyrocarbon, pyrolysis of hydrocarbon gases. 


\section{References}

1. Bogomolov V.O. Kozhan A.P., Bondarenko B.I., Khovavko O.I., Simeiko K.V. Kapsulirovanie kvarcevogo peska pirouglerodom $\mathrm{V}$ jelektrotermicheskom psevdoozhizhenom sloe [Research of the process of quartz sand encapsulation by pyrolytic carbon]. Energotehnologii $i$ resursozberezhenie [Energy Technologies and Resource Saving]. 2013, No. 5. p. 36-40. (Rus.)

2. Simeiko K.V. Ispolzovanie elektrotermicheskogo psevdoozhizhenogo sloya $\mathrm{v}$ kachestve vneshnego nagrevatelnogo elementa reaktora [Efficiency of electrothermal fluidized bed applying as the outer heating element of reactor]. Energotehnologii $i$ resursozberezhenie [Energy Technologies and Resource Saving]. 2015. No 1. pp. 58-64. (Rus.)

3. Simeiko K.V., Bezuglyiy V.K., Kozhan A.P., Bondarenko B.I. Issledovanie protsessa osazhdeniya tverdogo ugleroda pri pirolize uglevodorodnyih gazov [Research of the process of solid carbon deposition in the course of pyrolysis of hydrocarbon gases]. Energotehnologii $i$ resursozberezhenie [Energy Technologies and Resource Saving]. 2015. No. 2. pp. 18-24. (Rus.)

4. Simeiko K. Thermal influence of microdischarge plasma on the process of receiving of quartz sand encapsulated by pyrocarbon, Proccedings of the $\mathrm{Na}$ tional Aviation University. 2014. No. 2. pp. 131-135.

5. Simeiko K.V. Teplovi harakteristiki reaktoru dlya oderzhannya kapsulovanogo pirovugletsem kvartsevogo pisku pri prohodzhenni protsesu pirorizu metanu [Thermal characteristics of the reactor for pyrocarbon encapsulated quartz sand while passing the pyrolysis of methane]. Visnik SumDU. Seriya Tehnichni nauki [Sumy State University. Series Technical Sciences.]. 2013. No 4. pp. 119-123. (Ukr.)

6. Horbenko I. G. Zvuk, ul'trazvuk, infrazvuk [Sound, ultrasound, infrared sound]. Moscow : Znanie, 1986. 192 p. (Rus.)

7. Borodulja V.A., Rabinovich O.S., Vinogradov L.M., Greben'kov A.Zh., Akulich A.V., Ivanov V.E., Mihajlov A.M., Sidorovich A.M. Sintez vysokotehnologicheskih materialov $\mathrm{v}$ kipjashhem sloe : Novye podhody i perspektivy [Synthesis of hightech materials in the fluidized bed: new approaches and perspectives]. Abstracts and reports of the 14th Minsk International Forum on Heat and Mass Exchange (Minsk, Sept. 10-13, 2012). Minsk: Institute of Heat and Mass Transfer to them. A.V.Lykov of National Academy of Sciences of Belarus, 2012. pp. 228-231. (Rus.)

8. Gel'perin N.I., Ajnshtejn V.G., Kvasha V.B. Osnovy tehniki psevdoozhizhenija [Fundamentals of the fluidization technique]. Moscow : Himija, 1967. 664 p. (Rus.)

9. Kozhan A.P. Ispol'zovanie jelektrotermicheskih psevdoozhizhennyh sistem primenitel'no $k$ vyskotemperaturnoj pererabotke prirodnogo gaza [Use of electrothermal fluidized systems with reference to high-temperature processing of natural gas] : Avtoref. Dis. ... Cand. of Techn. Sci. Kiev, 1979. 19 p. (Rus.) 